common and distinct specificities at different sites of hydrolysis. $\beta$-lactoglobulin hydrolysis with these enzymes released peptides which had lost, respectively, 26 and $72 \%$ of their antigenicity. These enzymatic specificities were complementary to those of pepsin, chymotrypsin and trypsin. The residual antigenicity of $\beta$-lactoglobulin was thus decreased $12 \%$ with the use of elastase I in addition to the gastric and pancreatic mixture. This effect was greater with elastase II which reduced the $\beta$-lactoglobulin antigenicity by $35 \%$. According to these results, both elastase enzymes, and particularly elastase II, seemed to be efficient at improving the digestion of bovine lactoserum proteins in the preparations of infant hypoallergenic formulas.

\section{Pancreatic elastases I and II. Postnatal development in calves and pigs.} $M$ Gestin 1, I Le Huërou-Luron 1, C Desbois 1 , J Peiniau 2, A Aumaitre 2, R Toullec 1 , P Guilloteau 1 (' Laboratoire du jeune ruminant; 2 Station de recherches porcines; Inra, Rennes, France)

Globular bovine lactoserum proteins such as $\alpha$-lactalbumin and $\beta$-lactoglobulin are the most commonly used proteins in infant formulas together with bovine caseins. Intolerance to those proteins could be partially due to deficient proteolytic equipment in the baby's digestive tract. Because of its significant action on globular proteins, pancreatic elastase II is probably one of the enzymes implicated. In humans, this enzyme would be present at low levels at birth and its concentration would increase up to 24 months of age while the infant intolerance reactions are disappearing. Recent studies showed that elastase II and to a lesser extent, elastase I, had an hypoantigenic action on $\beta$-lactoglobulin. Elastase II ontogenesis has not been investigated so far in the calf (which digest cow milk proteins very efficiently) or in the pig (one of the species commonly used as a human model). The purpose of this study was to measure the postnatal development of pancreatic activities of elastases I and II in calves and pigs.

Four groups of calves $(n=18)$ and three groups of pigs $(n=18)$ were used. Calves and pigs of the first groups were sacrificed at birth while those of the remaining groups were milk-fed until slaughter on days 7, 21 and 119 for the former and on days 10 and 21 for the latter. Elastolytic activities were determined spectrophotometrically using specific synthetic substrates. Chymotrypsin and elastase I also hydrolyse the elastase II substrate, thus their activities were substracted in order to calculate the true elastase II activity.

The postnatal elastase II pattern was similar in both species: the specific activity was maximum at birth and declined sharply thereafter. Refering to the 0 day values, it was 52 and $68 \%$ lower in 21-day-old pigs and calves, respectively, and $96 \%$ lower in 119-day-old calves. In contrast, in calves the elastase I activity was five-fold greater at 119 days than at birth while in pigs it did not show any variation.

Elastases I and II (which seem to be implicated in allergenic protein hydrolysis in humans) are present as early as birth in both species. The early high level of elastase II activity would indicate an essential action in a period when the elastase I has a lower level. The change in its concentration with age is similar to that observed for other enzymes which play a prominent part in milk digestion. This work will be completed by measurement of elastases I and II activities in infant duodenal contents, especially in milk atopic patients.

This work was supported by La Région Bretagne. 